\title{
Cost and E-level analysis of different dwelling types and different heating systems with or without heat exchanger
}

\author{
A. Audenaert \\ L. De Boeck \\ K. Geudens \\ M. Buyle
}
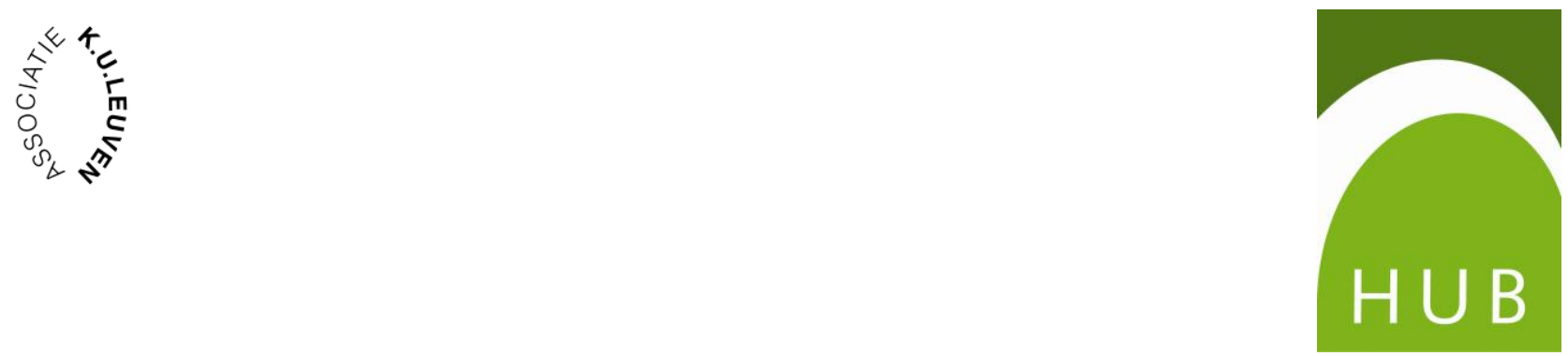
Cost and E-level analysis of different dwelling types and different heating systems with or without heat exchanger

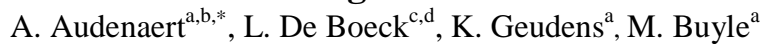

${ }^{a}$ Artesis Hogeschool Antwerpen, Paardenmarkt 92, 2000 Antwerp, Belgium

${ }^{\mathrm{b}}$ Faculty of Applied Economics, Universiteit Antwerpen, Prinsstraat 13, 2000 Antwerp, Belgium

${ }^{\mathrm{c}}$ Center for Informatics, Modeling and Simulation, HUBrussel, Stormstraat 2, 1000 Brussels, Belgium

${ }^{\mathrm{d}}$ Affiliated researcher Research Center for Operations Management, Faculty of Business and Economics,

Katholieke Universiteit Leuven, Naamsestraat 69, 3000 Leuven, Belgium

\begin{abstract}
Improving energy performance of buildings has become a key goal in managing energy demand. In this context, Europe produced the Energy Performance of Buildings Directive (EPBD). Flanders (Belgium) converted this directive into the 'Energy Performance and Interior Climate' (EPB). Taking into account this EPB standard, this study will undertake a cost analysis of different heating systems (condensing gas boiler, non-condensing gas boiler, oil boiler, and heat pump) and ventilation systems (C and D) and investigate their influence on the E-level. The analysis is performed for three representative types of dwellings in Flanders: a terraced, semi-detached and detached dwelling. The analysis clearly indicates that a condensing gas boiler in combination with the heat exchanger is most advantageous: it is the cheapest heating system and generates the lowest E-level. This makes the condensing gas boiler the best choice for all dwelling types.
\end{abstract}

\title{
1. Introduction and literature
}

The world energy is rapidly growing, raising concerns over difficulties in energy supply, exhaustion of energy resources and impact on the environment (see e.g. Pérez-Lombarda et al., 2008). It is therefore appropriate to reduce the ecological footprint. Also the heating of houses has a major effect on this footprint. As shown in Fig. 1 (Audenaert et al., 2008), housekeeping is responsible for $12 \%$ of the greenhouse gases. In addition with the $5 \%$ of the commercial premises, this leads to a total of $17 \%$ of the greenhouse gases.

[Insert Fig. 1 about here]

Figure 1

The production of greenhouse gases.

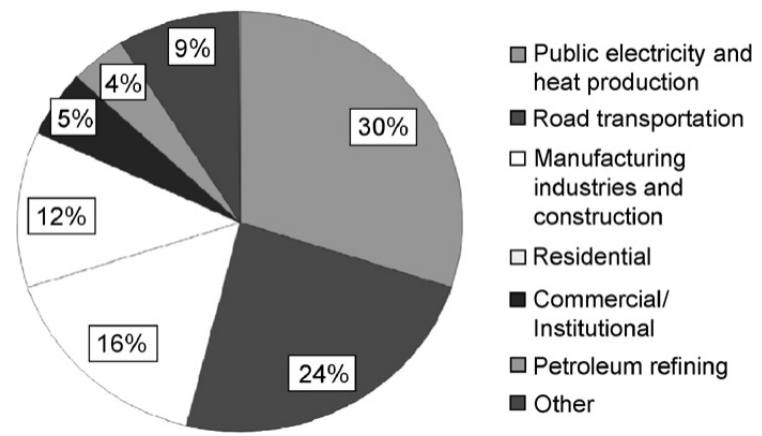

In this context, the Belgian government has created the energy performance regulations ('Energy Performance and Interior Climate' or EPB standard). This standard is a transposition of the Energy Performance of Buildings Directive (EPBD) (2002/91/EG) and the revised EPBD (2010/31/EU) issued by the European Union. In general, the directive aims to improve the energy performance of buildings in the European Union by promoting cost-effective

*Corresponding author. Tel.: +32 3213 79 35; fax: +32 32318670.

E-mail address: amaryllis.audenaert@artesis.be. 
solutions (see e.g. Pérez-Lombarda et al., 2008). The EPB standard has evolved in the course of the years. The current requirements and the future requirements approved by the Flemish government on December 17, 2010 (VEA, 2010) are listed in Table 1.

[Insert Table 1 about here]

Table 1

The EPB requirements for residential buildings.

\begin{tabular}{ll}
\hline Section & Requirement \\
\hline Insulation & maximum K-value 45 \\
& maximum K-value 40 from January 1,2012 on \\
& maximum U-values with changes from January 1,2012 and 2014 on \\
Indoor climate & Ventilation and reduction of risk of overheating \\
Energy performance & maximum E-level 100 for building application filed before 01/01/2010 \\
& maximum E-level 80 for building application filed between 01/01/2010-31/12/2011 \\
& maximum E-level 70 for building application filed between 01/01/2012-31/12/2013 \\
& maximum E-level 60 for building application filed after 31/12/2013 \\
& Maximum net energy for heating $70 \mathrm{kWh} / \mathrm{m}^{2}$ for building application of new \\
& construction filed after 31/12/2011 \\
\hline
\end{tabular}

We note that the $\mathrm{K}$-value is the overall insulation value of a dwelling, the U-values are the insulation values of the structural elements of the dwelling, and the E-level indicates the performance of a dwelling with respect to energy use. For the detailed information on this Kvalue, U-values and E-level, and how they are calculated, we refer to Audenaert et al. (2010).

We are interested in the E-level performance as well as the cost analysis, taking into account the time effect, for different heating systems, and for the three main types of dwellings present in Flanders (the terraced dwelling, the semi-detached dwelling, and the detached dwelling). The following heating systems are considered: the non-condensing gas boiler, the condensing gas boiler, the oil boiler, and the heat pump, all with or without heat exchanger. These heating systems are the most common.

Related literature on the influence of different heating systems on the E-level and total costs of dwellings is scarce. The reason lies probably in the energy-saving architectural measures rather focusing on insulation of buildings (see e.g. Panayi, 2004; Verbeekck and Hens, 2005; Audenaert et al., 2010) because thermal insulation of the existing building stock is considered as the largest potential source of $\mathrm{CO}_{2}$ emission saving (Petersdorff et al., 2006). Monahan and Powell (2011), Comakli (2008), Gustavssona and Joelsson (2007), and Van der Veken et al. (2006) are the only papers investigating the impact of different heating systems in dwellings on the energy use and costs. Monahan and Powell (2011) evaluate the energy use, emissions of $\mathrm{CO}_{2}$, and annual running costs for a case study comprising 14 newly constructed low energy affordable homes in the UK for the following energy typologies: ground sourced heat pumps, active solar (thermal and photovoltaic), passive solar and mechanical ventilation with heat recovery, and conventional high efficiency gas boiler. Comakli (2008) investigates energy efficiency and life cycle cost of conventional and condensing natural gas fired combi boilers in Erzurum (Turkey). Gustavssona and Joelsson (2007) compare different options for changing the heating system and electricity production for a Swedish detached house. They aim at an evaluation of the cost-effectiveness of reducing $\mathrm{CO}_{2}$ emission and primary energy use. Van der Veken et al. (2006) present the results of a simulation study in which different heat production systems (Micro Combined Heat and Power units, regular high efficiency boilers, condensing boilers, and water to water heat pumps) are installed in a Belgian terraced house, and in which high-temperature radiators, low-temperature radiators and floor heating are used as heat 
distribution systems. The evaluation is based on the gross energy consumption, the emission of greenhouse gases, the primary energy use and the net present value over the lifetime of the building.

The remainder of the paper is organized as follows. In section 2, we discuss the input data and methodology used. Section 3 represents the results. Section 4 concludes with the most important findings.

\section{Data and methodology}

The aim of the study is to search for the cheapest heating system and the heating system generating the best E-level. To accomplish this, an analysis is conducted using the EPB software Flanders for calculating the E-level, and a self-designed Excel file for calculating the total costs related to all heating systems. For more information on the EPB software Flanders, we refer to Audenaert et al. (2010).

The analysis will be performed for the three main types of dwellings present in Flanders (the terraced dwelling, the semi-detached dwelling, and the detached dwelling). The characteristics of these dwellings are represented in Table 2 (MW stands for mineral wool, PUR for polyurethane). Note that only the area of heat loss, the K-value, and the energy for tap water differ for the three dwellings types. The data in italic result from the EPB software Flanders, the other data are input of this software. The analysis starts from the terraced dwelling. In this dwelling, the closed walls are replaced by one full wall to obtain the semi-detached dwelling, and by two full walls to represent the detached dwelling. The latter one is represented in Fig. 2 . [Insert Table 2 about here]

[Insert Fig. 2 about here]

Table 2

The characteristics of dwellings.

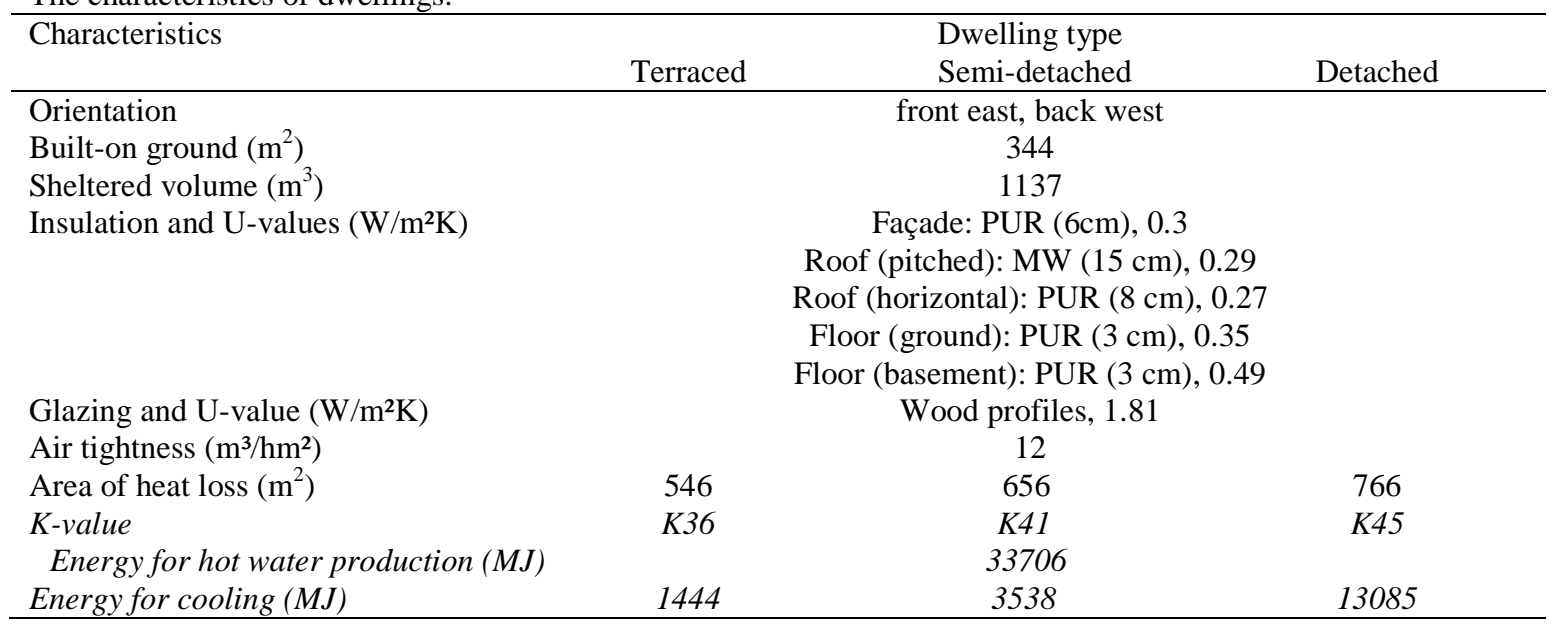


Figure 2

The detached dwelling.

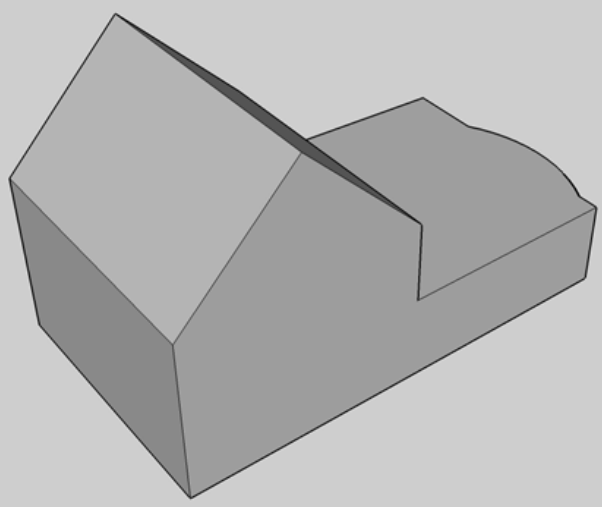

The heating and ventilation systems for each type of dwelling are varied and as a consequence also the E-level. Since heating represents by about 50 to $75 \%$ of household energy consumption (Audenaert et al., 2008), we will try to limit heat losses to a minimum. This will be achieved by good insulation and adequate ventilation. The ventilation system must ensure that sufficient fresh air is supplied to obtain a good indoor climate without too much heat loss. There exist four types of ventilation systems (see Fig. 3). System A has a natural air inflow and outflow. If both flows are generated mechanically, we have ventilation system D. If only one of these flows is generated mechanically, then we are dealing with system B (mechanical inflow) or $\mathrm{C}$ (mechanical outflow). However, since the EPB regulation requires to have at least a mechanical outflow and a system that complies with standard NBN D50-001, only ventilation systems C and D become relevant in our analysis (BIN, 1992).

[Insert Fig. 3 about here]

Figure 3

The different ventilation systems.

A: natural ventilation
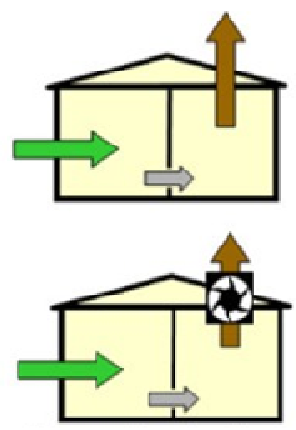

C: mechanical outflow
B: mechanical inflow

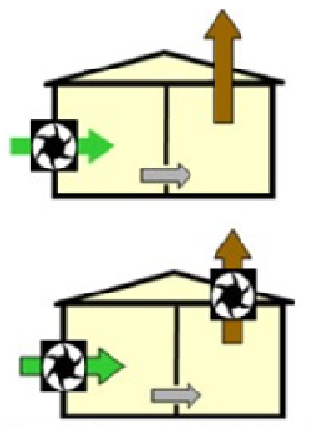

D: mechanical in- and outflow 
For the heating systems, we used the following heating appliances represented in Table 3. [Insert Table 3 about here]

Table 3

The heating appliances for each heating system.

\begin{tabular}{ll}
\hline Heating system & Heating appliance \\
\hline Condensing gas boiler & Logamax + , Buderus, and Ecotec + \\
Non-condensing gas boiler & Atmotec + , Logano G144, and Vitogas 200F \\
Oil boiler & VKO 248, Altron 30, and Bora CL \\
Heat pump & Vaillant 1, Vaillant 2, and ACV \\
\hline
\end{tabular}

In general, we can distinguish the following costs in calculating the total cost represented in Table 4.

[Insert Table 4 about here]

Table 4

Elements of the total costs.

\begin{tabular}{|c|c|c|c|}
\hline Cost heating system & $\begin{array}{l}\text { Cost heat exchanger } \\
\text { (only for ventilation } \\
\text { system D) }\end{array}$ & Energy cost (EC) & Financial benefit (FB) \\
\hline $\begin{array}{l}\text { Purchasing cost (PC) } \\
\text { Installation cost (IC) } \\
\text { Maintenance cost (not for } \\
\text { heat pump) (MC) }\end{array}$ & $\begin{array}{l}\text { Purchasing cost } \\
\text { Installation cost } \\
\text { Maintenance cost }\end{array}$ & $\begin{array}{l}\text { Depending on the energy } \\
\text { need, energy price and } \\
\text { efficiency of the heating } \\
\text { system/heat exchanger }\end{array}$ & $\begin{array}{l}\text { Amount depending on } \\
\text { how much the E-level is } \\
\text { below } 60\end{array}$ \\
\hline
\end{tabular}

The costs of the heating systems and heat exchanger are derived from the technical characteristics of these appliances. The energy cost for the heat exchanger, the condensing and non-condensing gas boiler, the oil boiler, and the heat pump are derived from the current energy prices for gas (Essent, 2011), oil (Goedkoopmazout, 2011) and electricity (Essent, 2011), the primary characteristic energy used for heating rooms (output from the EPB software Flanders), and some characteristics related to the heating system (e.g. efficiency oil boiler) and energy source (e.g. fixed and variable costs for gas). We omit the tax reduction and subsidy of the heat pump because the first one depends on the income and the latter on the rural district. The duration (or number of years) over which those costs are calculated is assumed to be 25 years for all heating systems. This time corresponds to the life of the heating system. The discount rate $d$ is fixed to 5.075, which is an interpolation between the interest rate on a 20year and 30-year mortgage taken from Immotheker (2011). The growth rates in energy prices are derived from Statbel (2011a) for gas and electricity and from Statbel (2011b) for oil. In Eq. (1), $T C^{H S}, T E C, T C^{H E}$, and $F B$ represent respectively the total cost of the heating system $(H S)$, the total energy cost for the heat exchanger $(H E)$ and heating rooms $(H R)$, the total cost of the heat exchanger, and the financial benefit. In what follows, we will omit $F B$ as the benefit is not applicable since no heating system succeeds in generating an E-level smaller than or equal to 60 . The subscript represents the year in which the related costs are made. ' 1 ' corresponds to the year in which the heating system/heat exchanger is purchased and installed. The net present value $(N P V)$ of the total costs is represented in Eqs. (1)-(4).

$N P V=T C^{H S}+T E C+T C^{H E}(-F B)$ 
$T C^{H S}=P C_{1}^{H S}+I C_{1}^{H S}+\sum_{t=2}^{25} \frac{M C_{t}^{H S}}{(1+d)^{t-1}}$

$T E C=\sum_{t=1}^{25} \frac{E C_{t}^{H R}}{(1+d)^{t-1}}+\sum_{t=1}^{25} \frac{E C_{t}^{H E}}{(1+d)^{t-1}}$

$T C^{H E}=P C_{1}^{H E}+I C_{1}^{H E}+\sum_{t=2}^{25} \frac{M C_{t}^{H E}}{(1+d)^{t-1}}$

Observe that $T C^{H E}$ is only included for ventilation system D (not for ventilation system C).

\section{Results}

In what follows, we represent respectively the E-level and the net present value in terms of all ventilation systems ( $\mathrm{C}$ or $\mathrm{D}$ ), all heating systems (condensing gas boiler, non-condensing gas boiler, oil boiler, and heat pump) and all dwelling types (terraced, semi-detached, and detached).

Using the EPB-software, we calculate how the E-level evolves using ventilations system $\mathrm{C}$ or $\mathrm{D}$ for the various dwelling types and heating systems. The results are represented in Figs. 4 and 5.

[Insert Fig. 4 about here]

[Insert Fig. 5 about here]

Figure 4

E-level for ventilation system $\mathrm{C}$ for the different dwelling types and heating systems.

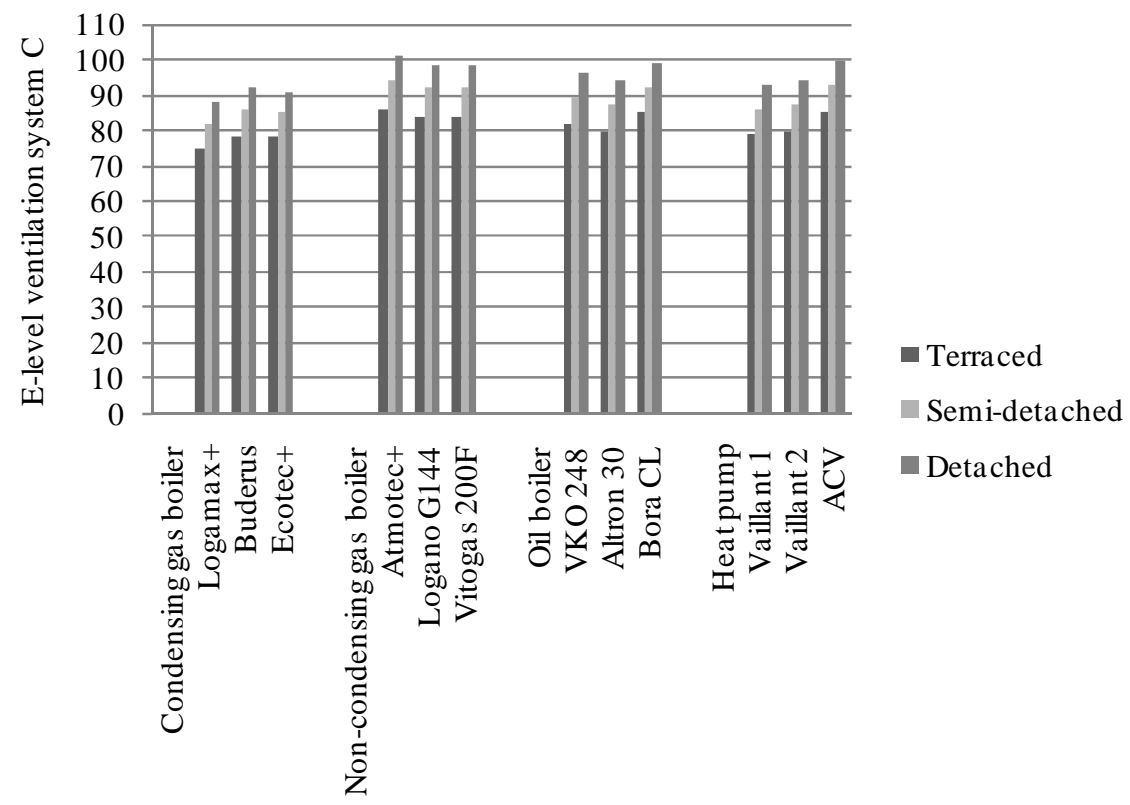


Figure 5

E-level for ventilation system D for the different dwelling types and heating systems.



We clearly observe from Fig. 4 that with ventilation system $C$ (without heat exchanger) the maximum E-level of 80 (see Table 1) is frequently exceeded. As such, it is best to choose ventilation system $\mathrm{D}$ (with heat exchanger). Further, there is a difference between the different dwelling types. The E-level is lower for the terraced compared to the semi-detached dwelling, and for the semi-detached compared to the detached dwelling. This has its origin in the insulation (see K-values in Table 2) which is larger for the semi-detached compared to the terraced dwelling, and for the detached compared to the semi-detached dwelling. It is also clear from Figs. 4 and 5 that the condensing gas boiler has the best performance in terms of E-level, followed by the heat pump and oil boiler. The non-condensing gas boiler performs worst.

The cost analysis $(N P V)$ is represented in Figs. 6 and 7. 
Figure 6

NPV of the total costs (in EUR) for ventilation system $\mathrm{C}$ for the different dwelling types and heating systems.



Figure 7

NPV of the total costs (in EUR) for ventilation system D for the different dwelling types and heating systems.

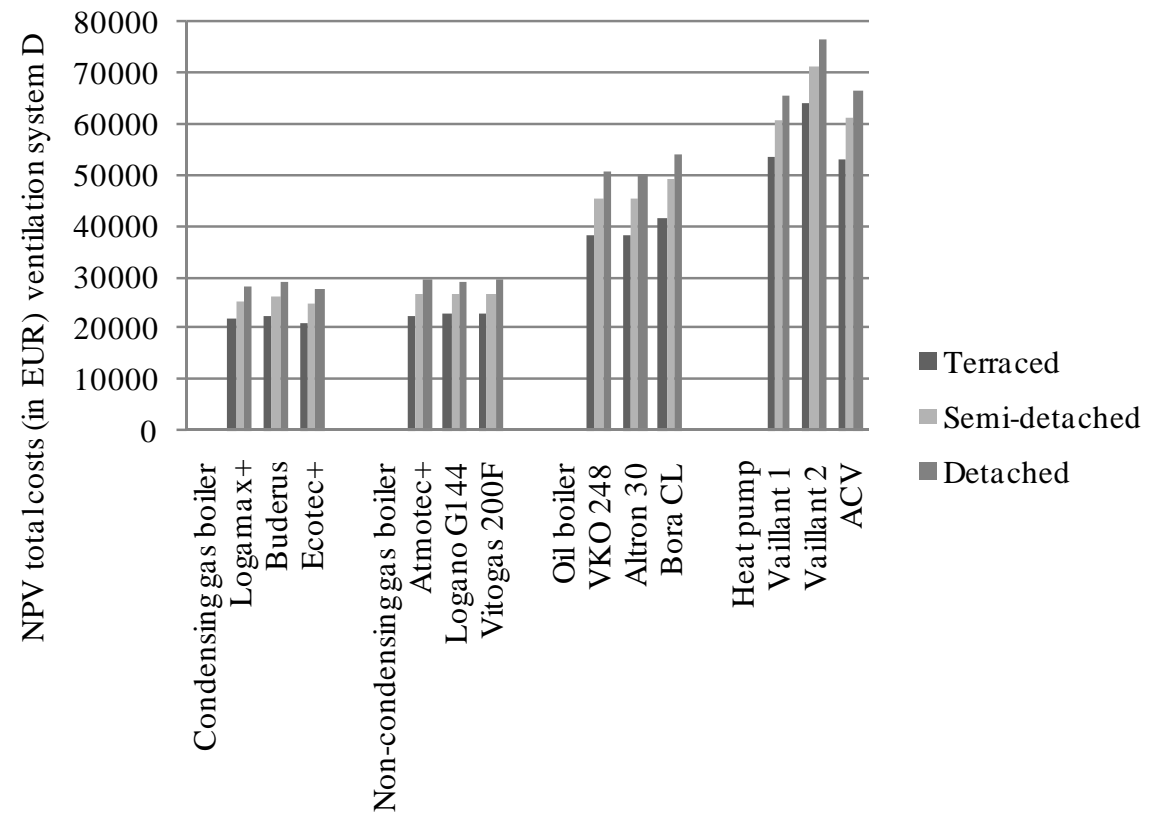

In Figs. 6 and 7, we observe the same performance as in Figs. 4 and 5 with respect to the ventilation systems and dwelling types: the NPV of the total costs is lower for ventilation system D compared to C, for the terraced compared to the semi-detached dwelling, and for the semi-detached compared to the detached dwelling. The NPV of the total costs for all gas boilers is better than that of oil boilers. This is caused by the energy prices: the use of fuel oil is still remarkably expensive over time. The low variable cost of a heat pump cannot ensure that 
the heat pump would be more profitable than other heating systems. This is due to the high purchasing price and installation cost. As such, the gas boiler is the most profitable heating system. A condensing gas boiler is slightly more profitable than a non-condensing gas boiler.

\section{Conclusions}

Improving energy performance of buildings has become a key goal in managing energy demand. In this context, we undertake an E-level and cost analysis of different heating systems (condensing gas boiler, non-condensing gas boiler, oil boiler, and heat pump) and ventilation systems (C and D) for three representative types of dwellings (terraced, semi-detached and detached dwelling) in Flanders. The conclusions are very obvious: the condensing gas boiler with heat exchanger outperforms all the rest in terms of E-level and costs. From this, one can conclude that a condensing gas boiler with heat exchanger is the best choice for any singlefamily dwelling type.

\section{References}

Audenaert, A., De Cleyn, S.H., Vankerckhove B. (2008). Economic analysis of passive houses and low-energy houses compared with standard houses. Energy Policy, 36(1), 47-55.

Audenaert, A., De Boeck, L., Roelants, K. (2010). Economic analysis of the profitability of energy-saving architectural measures for the achievement of the EPB-standard. Energy, 35(7), 2965-2971.

BIN. (1992). NBN D 50-001. Ventilation facilities in residential buildings. Belgian National Institute for Standardization. Brussels, Belgium

Comakli, K. (2008). Economic and environmental comparison of natural gas fired conventional and condensing combi boilers. Journal of the Energy Institute, 81(4), 242-246.

Essent (2011). See also: http://www.essent.be/nl/particulieren/productoverzicht/aardgas-promo [in Dutch].

Goedkoopmazout (2011). See also: http://www.goedkoopmazout.be [in Dutch].

Gustavssona, L., Joelsson, A. (2007). Energy conservation and conversion of electrical heating systems in detached houses. Energy and Buildings, 39(6), 717-726.

Immotheker. $\quad$ (2011). See also: http://www.immotheker.be/Immotheker3/Site_v3/Default.aspx?WPID=273\&L=N [in Dutch].

Monahan, J., Powell, J.C. (2011). A comparison of the energy and carbon implications of new systems of energy provision in new build housing in the UK. Energy Policy, 39(1), 290-298.

Panayi, P. (2004). Prioritising energy investments in new dwellings constructed in Cyprus. Renewable Energy, 29(5), 789-819.

Pérez-Lombarda, L., Ortizb, J., Poutb, C. (2008). A review on buildings energy consumption information. Energy and Buildings, 40(3), 394-398. 
Petersdorff, C., Boermans, T., Harnisch, J. (2006). Mitigation of $\mathrm{CO}_{2}$ emissions from the EU15 building stock - Beyond the EU directive on the energy performance of buildings. Environmental Science and Pollution Research 2006, 13(5), 350-358.

Statbel. (2011a). See also: http://statbel.fgov.be/nl/binaries/energiemarkt_2008_tcm325112137.pdf [in Dutch].

Statbel. (2011b). See also: http://statbel.fgov.be/nl/statistieken/cijfers/energie/prijzen/gemid_8/ [in Dutch].

Van der Veken, J., Hens, H., Peeters, L., Helsen, L., D'haeseleer, W. (2006). Economy, energy and ecology based comparison of heating systems in dwellings. In: Fazio, P., Ge, H., Rao, J., Desmarais, G. (eds.), Research in Building Physics and Building Engineering Book Series: Proceedings and Monographs in Engineering, Water and Earth Sciences, 661-668.

VEA. (2010). Principiële goedkeuring wijzigingsdecreet-besluit. Annex 1 - Nieuwsbrief 2010, nr. 7 (December). See also:

http://www2.vlaanderen.be/economie/energiesparen/epb/nb1007/annex1wijzigingsbesluit.pdf [in Dutch].

Verbeeck, G., Hens, H. (2005). Energy savings in retrofitted dwellings: economically viable? Energy and Buildings, 37(7), 747-754. 